\title{
Predictors of maternal and neonatal complications in patients with severe valve heart disease during pregnancy: a retrospective cohort study
}

Rania Hammami ( $\nabla$ raniahammami@yahoo.fr)

Hedi Chaker Hospital: Hopital Hedi Chaker https://orcid.org/0000-0003-1168-6450

Mohamed Ali Ibn Hadj

Hedi Chaker Hospital: Hopital Hedi Chaker

Yosra Mejdoub

Hedi Chaker Hospital: Hopital Hedi Chaker

Amine Bahloul

Hedi Chaker Hospital: Hopital Hedi Chaker

Selma Charfeddine

Hedi Chaker Hospital: Hopital Hedi Chaker

Leila Abid

Hedi Chaker Hospital: Hopital Hedi Chaker

Samir Kammoun

Hedi Chaker Hospital: Hopital Hedi Chaker

Abdallah Dammak

Hedi Chaker Hospital: Hopital Hedi Chaker

Kais Chaabene

Hedi Chaker Hospital: Hopital Hedi Chaker

\section{Research article}

Keywords: Pregnancy, severe valve heart disease, neonatal complications, prognosis

Posted Date: January 25th, 2021

DOI: https://doi.org/10.21203/rs.3.rs-91664/v2

License: (c) (i) This work is licensed under a Creative Commons Attribution 4.0 International License.

Read Full License 


\section{Abstract}

Background: The severe valve disease especially stenosis is a contraindication to conception according to World Health Organization. This situation is still encountered in countries with a high rheumatic fever prevalence. The objective of this study is to determine the predictors of maternal cardiac, obstetric and neonatal complications.

Methods: This is an observational study of all pregnant women with severe valvulopathy, delivered between 2010 and 2017.

Results: We included 60 pregnancies in 54 women. Cardiac complications occurred in 37 patients (61\%). In multivariate analysis, the predictors of these complications were parity $(O R=2.41, p=0.023)$, revelation of valvulopathy by pregnancy $(O R=6.34, p=0.025)$, severe mitral stenosis $(O R=6.84, p=$ $0.035)$ and systolic pulmonary arterial pressure $(O R=1.08, p=0.01)$. Obstetrical complications were noted in 19 women $(31.8 \%)$. The predictors of these complications were primiparity $(O R=5.22, p=$ $0.032)$, multiple valve disease $(O R=5.26, p=0.028)$, systolic pulmonary arterial pressure $(O R=1.04, p=$ $0.04)$ and treatment with vitamin $\mathrm{K}$ antagonist $(\mathrm{OR}=8.71, \mathrm{p}=0.04)$. Neonatal complications were noted in $39 \%$ of new-borns. The predictors of these complications were the occurrence of obstetric complications $(O R=15.48, p=0.001)$ and the revelation of valvulopathy by pregnancy $(O R=6.95, p=$ 0.017).

Conclusions: The revelation of valve disease by pregnancy is a predictor not only of cardiac complication but also of neonatal complications, thus valve disease screening during pre-conceptional counselling is so crucial.

\section{Background}

Pregnancy is associated with several hemodynamic modifications which could disturb the function of cardiac pump, especially in women with cardiac diseases. In fact, the prevalence of heart disease in pregnant women is estimated between 1 and 4\% [1,2]. According to the largest multicentre registry of heart diseases in pregnant women "ROPAC", the most prevalent cardiac diseases are rheumatic valvular pathology in emerging countries and congenital heart disease in developed countries [3,4]. The World Health Organisation (WHO) considers severe stenotic valve heart disease as a contraindication to conception (WHO IV category) [5]. Giving that rheumatic heart disease remains prevalent in our country [6], managing pregnant women with such conditions is still encountered in our daily practice and is a challenging situation for obstetricians, cardiologists and anaesthesiologists. In fact, we have to deal with two main challenges; the first one is: should we opt for stopping the pregnancy considering maternal and foetal risks. The second one is: what is the most appropriate mode of delivery in case of carrying on the pregnancy.

Thus, this study aims at assessing both maternal and neonatal prognosis in pregnant women with at least one severe cardiac valve disease and identifying the risks involved. 


\section{Methods}

\section{Population}

This is a transversal retrospective study that includes a cohort of all consecutive pregnant women with at least one severe organic valve disease during the period between January 2010 and December 2017, managed in both the cardiology and the gynaecology departments of our Hospital. We excluded pregnancies in patients with cardiac valve prothesis, as well as pregnancies in women who underwent termination or had a spontaneous abortion or a miscarriage. Baseline clinical, electrocardiographic, and echocardiographic variables were collected from the medical files and included: maternal age, educational level, parity, gravidity, cardiac lesions, prior cardiac interventions, New York Heart Association (NYHA) functional class, cardiac rhythm, ventricular systolic function, valvular function and pulmonary arterial systolic pressure. The severity of valve lesions was assessed according to the criteria of the guidelines of the European Society of Cardiology [7].

The included women were contacted to get information about both the contraception use after delivery and the eventual new pregnancies before treating the valve disease.

Women who refused to give their verbal consent were excluded from the study. The study was approved by the ethic committee of the hospital "Committee of person protection SUD: CPP SUD", the reference of the study was $0245 / 2020$.

\section{Endpoints}

Maternal cardiac complications were defined as maternal cardiac death, new episode of arrhythmia requiring treatment, heart failure, thromboembolic events, and clinical overdose with the anticoagulants, endocarditis and hospitalization for cardiac reason during pregnancy and up to 1 week postpartum.

Obstetrical complications were defined as maternal non-cardiac death up to 1 week postpartum, gestational diabetes, pre-eclampsia, premature delivery threats, premature rupture of membranes and perpartum haemorrhagic complications (increased blood loss, $>500 \mathrm{~mL}$ after vaginal delivery or $>1000$ $\mathrm{mL}$ after caesarean delivery, up until 24 hours postpartum).

Neonatal complications were defined as premature birth $<37$ weeks, small-for-gestational-age ( $<10$ th centile), hospitalization in neonatology department and neonatal death up to 1 week after delivery.

\section{Statistical Analysis}

Categorical variables are presented as frequencies and percentages and differences between groups are assessed using $\chi 2$ tests. Continuous variables are presented as mean and standard deviation, or as median and first and third quartiles as appropriate, and differences are assessed using Student's t-test or Mann-Whitney $U$ tests depending on the data distribution. Univariate analysis, to identify predictors of adverse events, was performed using chi-square, Fisher exact, or Student's t-tests as appropriate. 
Univariate predictors of adverse events with $p$ values $<0.2$ were entered into a multivariate logistic regression model using backward elimination with a significant level of 0.05 .

\section{Results}

Our cohort included 60 pregnancies in 54 women with at least one severe valve disease. It was about 59 spontaneous singleton pregnancies and one assisted twin pregnancy. In fact, during the study period 80624 deliveries were ensured in our hospital. Six hundred thirty nine cardiac ultrasound exams were performed in pregnant women or during the first week after delivery. The prevalence of valve heart disease was $0.49 \%$. The prevalence of severe lesions was $0.074 \%$ (about 7 patients among 10000 deliveries).

The mean age of our cohort was $32.55 \pm 5.6$ years. More than half of the patients were symptomatic of at least stage II dyspnea during the first trimester of pregnancy, however $60 \%$ of women showed also anaemia on their biological analysis. Baseline characteristics are shown in Table 1.

Pregnancy had revealed the valve disease in 31 patients (52\%) and the mean term of diagnosis was $27 \pm$ 6.7 weeks of amenorrhea (range: 12-38 weeks).

The median term of delivery was 38 weeks of amenorrhea (range: 30-42 weeks); preterm delivery occurred in 12 patients (20\%) and only one case exceeded normal term. The latter patient was not aware of her valvulopathy which was discovered following an acute pulmonary oedema occurred during labour.

The revelation mode of the valve disease was pulmonary oedema in most cases ( 21 patients, $68 \%$ ). Nearly, half of our patients didn't plan the current pregnancy. In this group, only 13 women (43.3\%) used a contraceptive method at the time of conception (micro-progestative in 5 cases, intra-uterin device in one patient and periodic continence in 7 patients). The most prevalent valve disease was mitral stenosis (43 patients, 67\%). Eight patients underwent percutaneous mitral comissurotomy during pregnancy; the procedure was not performed in 24 women either because of contraindications or because of anatomically unfavourable valve. However, 11 patients didn't benefit from this procedure despite the theoretical feasibility, as they refused the intervention or for the late diagnosis of valvulopathy (during peripartum). Among the 8 women who received mitral commissurotomy, only one vaginal delivery was achieved in 7 patients; the indication for caesarean section in the last patient was obstetrical.

Most of our patients (68\%) had delivered by caesarean section. In three patients an assisted delivery with oxytocin was performed as the valvulopathy was discovered late, in post-partum. The indication for caesarean section was in most cases cardiac (73\%) and performed on a scheduled basis (88\%).

As far as new borns are concerned, we notice that the median birth weight was $3000 \mathrm{~g}$ (range: $1500 \mathrm{~g}$ $-3750 \mathrm{~g}$ ). The median Apgar score on the first minute was 9 (range: 3-9). Apgar score at 5 minutes was significantly lower in preterm newborns than in full term newborns : $7.16 \pm 1.61$ versus $8.66 \pm 0.73, p=$ 0.01 . 
All new-borns had an Apgar score $\geq 7$ on the 5th minute, except for one neonate, born from twin pregnancy, who had a score $=3$ at birth. He had been hospitalized in neonatology for 17 days because of respiratory distress and the evolution was favourable.

In our population, 44 cardiac events occurred in 37 pregnancies (61.6\%). The most cardiac events (95\%) occurred during the antepartum period, while the other events occurred during labour and delivery or in the postpartum week following discharge (5\%) (Table 2 and 3 ). The most common cardiac complications were heart failure (36 patients) and arrhythmias. Only one case of cardiac arrest happened in one patient with twin pregnancy because of ventricle arrhythmia: this event occurred two hours after a mitral commissurotomy, a severe hypokalaemia was noticed. Thus, the woman was transferred to reanimation department; the evolution was favourable. And a foetal extraction was achieved at 30 gestational weeks.

Twenty three obstetrical events occurred in 19 pregnancies (31.8\%) (Table 4 and 5) and 27 foetal events occurred in 24 new-borns (40\%) (Table 6 and 7). Overall, no case of maternal or neonatal death was observed. Three patients showed preeclampsia and were in fact treated with intravenous diuretic because of pulmonary oedema.

Pregnancies with cardiac complications showed significantly more foetal events (51.4\% versus $17.4 \%$, $\mathrm{p}=0.009)$ but no differences were observed as far as obstetric complications are concerned $(37.8 \%$ versus $21.7 \%, p=0.19)$.

The rate of preterm delivery was $20 \%$ in our series ( 12 deliveries). It was about two cases of spontaneous prematurity and 10 cases of iatrogenic prematurity. Nine patients $(75 \%)$ among those with preterm delivery had a severe mitral stenosis. Pulmonary arterial pressure was significantly higher in the preterm delivery patients $(60.08 \pm 16.81$ versus $48.08 \pm 15.94 \mathrm{mmHg}, p=0.04)$. After one year of the current pregnancy, only 31 women used contraception (51.7\%). And among the other women, 6 patients had a new pregnancy even before treating the severe valve heart disease.

\section{Discussion}

Cardiovascular diseases are the most common causes of maternal death during pregnancy[8]. Knowledge of the risks associated with such conditions in pregnant women and their management is of pivotal importance. However, the number of published cases is limited and most recommendations are class $\mathrm{C}$ even in the most recent guidelines [9]. The tolerance of valvular heart disease during pregnancy is little recognized since the prevalence of rheumatoid arthritis is decreasing. However, nowadays there is an increase in the age of pregnant women; thus the prevalence of pregnant woman with severe cardiac valve disease remains steady. The current study, was carried out to evaluate our maternofoetal outcomes in pregnant women with severe valve lesions. The recently published Global Rheumatic Heart Disease Registry (REMEDY) included 3343 patients with rheumatic heart disease in 12 African countries, India and Yemen; the median age was 28 years [10]. The majority (63.9\%) had moderate to severe valvulopathy which was complicated by congestive heart failure in $33.4 \%$, pulmonary hypertension in $28.8 \%$, atrial fibrillation in $21.8 \%$, stroke in $7.1 \%$, and infectious endocarditis in $4 \%$ and major bleeding in $2.7 \%$. In 1,825 
women of reproductive age (aged 12-51), only 3.6\% used contraception. In a Tunisian study analysing the epidemiological profile of cardiac women who gave birth in a Tunis maternity center between January 2010 and December 2012, out of 19655 deliveries studied, the prevalence of heart disease was 1 in 351 deliveries $(0.285 \%)$. The mean age was $30.89 \pm 5.3$ years (ranges between 21 and 42 years). Out of the 56 cases of cardiac women, 35 patients $(62.5 \%)$ had valvulopathy , which means its prevalence of $0.17 \%$ [11]. In our cohort, the mean age was $32.5 \pm 5.6$ years and the prevalence of heart valve disease was about $0.49 \%$ and of severe disease was estimated at $0.074 \%$.

Cardiac complications are frequent in pregnant women with cardiac valve diseases and varies between $13 \%$ and $35,6 \%$ according to previous studies [12-16] (Table 8 ) . Certainly the rate of complications will be higher in women with severe lesions, especially when the condition is discovered only during pregnancy. In the CAPREG II study, the overall maternal cardiac event rate during pregnancy for mWHO I, $\mathrm{mWHO} \mathrm{II}, \mathrm{mWHO} \mathrm{III}$, and $\mathrm{mWHO}$ IV was $3.1 \%, 12.8 \%, 21.1 \%$, and $35.6 \%$, respectively. In our cohort two patients out of three showed cardiac events. Pulmonary oedema seems to be the most prevalent complications; the advancement of therapeutic strategies improved the prognosis. Maternal cardiac death or cardiac arrest became rare, in the recent CAPREG II study it occurred in 11 pregnancies $(0.6 \%)$ [13]; No cardiac death occurred during the experience of a tertiary care center including women with pulmonary hypertension, [17]. In our series no maternal death was noted; only one case of cardiac arrest occurred because of dyskaliemia and the recovery was obtained. However, cardiac mortality remains much higher than that in the general obstetric population [18-21].

Several studies tried not only to determine the predictors of cardiac events but also to analyse them in order to conclude the scores.

The multicenteric CARPREG (Cardiac Disease in Pregnancy Study) including patients both with congenital and acquired diseases, was the first to develop such risk index. Predictors of cardiac events were: left heart obstruction, cyanosis or dyspnea before pregnancy, cardiac antecedents and systolic LV dysfunction [15,22]. In the European Registry of Pregnancy and Heart Disease (ROPAC), including 2966 women, valve heart disease account for $25 \%$ of pregnant women with cardiovascular disease. Mitral diseases, both stenosis and regurgitation, were the most common valvular lesions (63\%), followed by aortic valve disease (23\%) (Table 8). In this registry, signs of heart failure before pregnancy, atrial fibrillation and no previous cardiac intervention were strong predictors of cardiac events. In our cohort, cardiac complications occurred especially in stenotic lesions; regurgitant lesions were well tolerated and didn't affect the possibility of carrying a pregnancy to full term. In stenotic lesions, increased cardiac output causes a significant rise in transvalvular gradient of $50 \%$, mainly between the first and second trimesters, [23]. That's why congestive heart failure occurred more commonly in the third trimester or early postpartum, whereas most arrhythmias occurred in the antenatal period.

Mitral stenosis was the most untolerated valve disease and was found as independent predictor of cardiac complications. In fact, pregnancy period is characterized by an increase of cardiac output brought by increased heart rate and stroke volume, and oppositely a decrease of peripheral resistance by 
a peripheral vasodilatation. The drop of vascular resistance explains the tolerance of regurgitant lesions [6,24-26].

Pregnancy outcomes in two large centers in the United States reported a risk of pulmonary oedema occurrence in pregnant women with mild, moderate and severe mitral stenosis, respectively between $11 \%$ and $24 \%, 34 \%$ and $61 \%$, and $56 \%$ and $78 \%$. The rate of occurrence of atrial fibrillation varied between 0 and $7 \%$ in case of mild stenosis, 10 and $22 \%$ in the case of moderate stenosis and between 22 and $33 \%$ in case of severe lesions[16,27].

Percutaneous mitral dilation seems to improve remarkably the hemodynamic condition of these patients, then allow even a vaginal delivery in most cases. According to the recent ESC guidelines, Intervention should be considered before pregnancy in patients with MS and valve area $<1.5 \mathrm{~cm}^{2}$ and should be considered in pregnant patients with severe symptoms or systolic pulmonary artery pressure $>50 \mathrm{mmHg}$ despite medical therapy [9].

In our study, the revelation of cardiac valve disease by pregnancy was also found as strong predictor not only of cardiac complications but also neonatal complications, this result accords with other predictors found in the ROPAC registry or the CAPREG II study which is the lack of intervention before pregnancy as well as the delayed pregnancy assessment. Therefore, it is strongly recommended to assess prepregnancy risk and to counsel all women with known or suspected congenital or acquired cardiovascular and aortic disease [28]. It is also recommended to perform risk assessment in all women with cardiac diseases of childbearing age before as well as after conception, using the mWHO classification of maternal risk[28]. Generally, women who receive late pregnancy assessment had more frequent adverse cardiac outcomes during pregnancy, which may be attributed to delayed access to appropriate risk stratification, follow-up, and management plan.

But we noted that in our practice, despite the fact that the rate of illiteracy among women was low (3\%), the use of contraception is infrequent, as is the evidence of new pregnancies in cardiac women who had already cardiac complications during pregnancy before treating their heart disease. The cardiologist plays a pivotal role in the therapeutic education of these women and the prescription of an adequate contraception while discussing with the gynecologist.

The obstetrical risk remains poorly described in literature. The main parameter to be evaluated is the mode of delivery, which depends, in this context, on the maternal tolerance of pushing efforts and the possibility of epidural analgesia. According to the recent guidelines a delivery plan should be made between 20-30 weeks of pregnancy detailing induction, management of labour, delivery, and post-partum following up; Moreover the Induction of labour should be considered at 40 weeks of gestation in all women with cardiac disease [9].

Obstetric complications were 3 to 4 times more common in our population compared to the ROPAC and CAPREG studies (Table 8). The low parity (nulliparous or primiparous) is a predictor of obstetrical events in many studies, especially that it increases the risk of preeclampsia [29] (Table 8). 
In our cohort premature labour threat was the most common complication. This is mainly due to both uterine muscle hypoxia as well as to acute heart failure, commonly occurred in our patients

Pre-eclampsia was more common in women with aortic valve disease and left ventricle dysfunction because of low cardiac output and, as expected, in nulliparous women and those with pre-existing hypertension. In our series, all the cases of preeclampsia occurred in women treated with intravenous diuretic because of acute heart failure. This is a frequently faced challenge. Diuretic results in a placenta hypoperfusion which is the main mechanism of preeclampsia and normally diuretic should be avoided in such patients. The anticoagulant use is also a predictor of obstetrical complications mainly haemorrhage. In our cohort, this factor increases 8 times the risk of obstetrical events, the association between haemorrhage and anaemia frequently diagnosed in our patients will worsen the prognosis and result in heart decompensation. That's why it is recommended to anticipate the timing of delivery to ensure a safe and an effective peripartum anticoagulation.

The neonatal prognosis is closely correlated with maternal prognosis. Anyway, in our series we have noted the occurrence of obstetric complications $(O R=15.48, p=0.001)$ and the revelation of valvulopathy by pregnancy $(O R=6.95, p=0.017)$ as strong predictors of neonatal complications. In fact, the delayed discovery of valvulopathy may expose the foetus to a longer duration of hemodynamic stress, especially with a risk of placental hypoperfusion, hypotrophy and prematurity. The immunological status of these new-borns will also be precarious with a higher risk of hospitalization in neonatology. In the ROPAC registry, the rate of foetal complications among women with WHO IV heart disease was $31 \%$, a comparable rate to our series that was/ represented $40 \%$. Predictors of these complications in ROPAC were multigestity, treatment with anticoagulant, diabetes, and life in developing countries (table 8).

Symptomatic women (NYHA class III-IV), and oral anticoagulants, were the main reasons for induced preterm delivery. In case of spontaneous prematurity both inflammatory processes, and utero-placental ischemia can initiate preterm labour [30]. Certainly, maternal hypoxia increases cytokines and oxygen free radicals, which may cause abnormal placentation; these conditions mostly occurred in woman with congenital heart disease [31]. In our cohort most cases of premature delivery were induced, that's why pulmonary systolic pressure were significantly higher in mothers of preterm babies. In a Japanese cohort including 857 women with cardiac disease, ischemic cardiac disease followed by valve heart disease were related to the highest risk of induced prematurity, respectively $48.3 \%$ and $44.3 \%$; the rate of caesarean section was respectively $81.7 \%$ and $68.8 \%$. In our series, we noted only $20 \%$ of prematurity; previous studies showed that both induced and spontaneous preterm birth were less common in developing countries than in developed countries. This was explained by the advanced age with uterine dysfunction for the spontaneous prematurity and a quicker access to obstetric care facilities in developed countries.

\section{Study limitations}

The main limitations of our study involve the retrospective design from one hand and the small sample size from the other hand. These two limits could be explained by the low prevalence of severe valve 
disease among pregnant women; as it contra-indicates the conception. Moreover, we included only term pregnancies since abortions and stopped pregnancies are multifactorial, and so we are unable to conclude that there is a relationship between these obstetric events and the severity of valvulopathies.

\section{Conclusions}

To conclude, our cohort demonstrates that women with severe heart valve diseases should be counselled about the pregnancy risks and foetal problems. It is crucial to early detect such cardiac lesions during premarital consultation, through a meticulous interrogation on functional tolerance to the effort and an attentive cardiac auscultation.

Since mitral stenosis is the most commonly encountered lesion, the percutaneous treatment should be attempted whenever possible and performed by experimented operator; it improves the hemodynamic conditions and offers more chance of vaginal delivery.

As for the obstetricians, they should give priority to vaginal delivery with triggering as much as possible, use epidural analgesia widely and shorten delivery as much as possible especially in women treated with anticoagulants.

Finally, in developing countries, much more efforts should be given to the organisation of contraception in cardiac women, which necessitates a close collaboration between both the cardiologist and the gynaecologist.

\section{Abbreviations}

WHO: World Health Organisation

NYHA: New York Heart Association

\section{Declarations}

Ethics approval and consent to participate: the research was approved by the committee of the hospital (Committee of person Protection SUD: CPP Sud, the refrence of this study was 0245/2020)

The ethic committee approved a verbally consent as patients will be contacted by phone.

Consent for publication: not applicable (there are no images or other personal or clinical details of participants that compromise anonymity)

Availability of data and material: the data and material are available ( we add an spss file in the supplement materiel)

Competing interests: The authors declare no competing interests 
Funding: No funding was obtained for this study

\section{Authors' contributions:}

all authors have read and approved the manuscript

$\mathrm{RH}$ wrote the paper

M A B: collected the data and contacted the patients by phone

Y M: achieved the statistical analysis of the paper

$A B, S C, L A, S K, A D$, and $K C$ : reviewed and corrected the paper

Acknowledgements: Not Applicable

\section{References}

1. Elkayam U, Goland S, Pieper PG, Silverside CK. High-Risk Cardiac Disease in Pregnancy: Part I. J Am Coll Cardiol. $2016 \mathrm{Jul}$ 26;68(4):396-410.

2. Creanga AA, Berg CJ, Syverson C, Seed K, Bruce FC, Callaghan WM. Pregnancy-related mortality in the United States, 2006-2010. Obstet Gynecol. 2015 Jan;125(1):5-12.

3. van Hagen IM, Boersma E, Johnson MR, Thorne SA, Parsonage WA, Escribano Subías P, et al. Global cardiac risk assessment in the Registry Of Pregnancy And Cardiac disease: results of a registry from the European Society of Cardiology. Eur J Heart Fail. 2016;18(5):523-33.

4. van Hagen IM, Baart S, Fong Soe Khioe R, Sliwa-Hahnle K, Taha N, Lelonek M, et al. Influence of socioeconomic factors on pregnancy outcome in women with structural heart disease. Heart $\mathrm{Br}$ Card Soc. 2018 May;104(9):745-752.

5. Pijuan-Domènech A, Galian L, Goya M, Casellas M, Merced C, Ferreira-Gonzalez I, Marsal-Mora JR, Dos-Subirà L, Subirana-Domènech MT, Pedrosa V, Baró-Marine F, Manrique S, Casaldàliga-Ferrer J, Tornos P, Cabero L, Garcia-Dorado D. Cardiac complications during pregnancy are better predicted with the modified WHO risk score. Int J Cardiol. 2015 Sep 15;195:149-54.

6. Triki F, Jdidi J, Abid D, Tabbabi N, Charfeddine S, Ben Kahla S, et al. Characteristics, aetiological spectrum and management of valvular heart disease in a Tunisian cardiovascular centre. Arch Cardiovasc Dis. 2017 Sep;110(8-9):439-46.

7. Baumgartner H, Falk V, Bax JJ, De Bonis M, Hamm C, Holm PJ, et al. 2017 ESC/EACTS Guidelines for the management of valvular heart disease. Eur Heart J. 2017 Sep 21;38(36):2739-91.

8. Creanga AA, Berg CJ, Syverson C, Seed K, Bruce FC, Callaghan WM. Pregnancy-related mortality in the United States, 2006-2010. Obstet Gynecol. 2015 Jan;125(1):5-12.

9. Regitz-Zagrosek V, Roos-Hesselink JW, Bauersachs J, Blomström-Lundqvist C, Cífková R, De Bonis M, et al. 2018 ESC Guidelines for the management of cardiovascular diseases during pregnancy. Eur 
Heart J. 2018 Sep 7;39(34):3165-241.

10. Zühlke L, Engel ME, Karthikeyan G, Rangarajan S, Mackie P, Cupido B, et al. Characteristics, complications, and gaps in evidence-based interventions in rheumatic heart disease: the Global Rheumatic Heart Disease Registry (the REMEDY study). Eur Heart J. 2015 May 7;36(18):11151122a.

11. Khemiri K, Jenayah AA, Boudaya F, Hamdi A, Meskhi S, Sfar E, et al. Profil épidémiologique des femmes enceintes cardiaques dans le centre de maternité de Tunis: expérience du service A. Pan Afr Med J. 2015 Jun 22;21(140):1-4.

12. Aydin E, Ozyuncu O, Kasapoglu D, Orgul G, Ozer N, Yurdakok M, et al. Clinical analyses of 383 cases with maternal cardiac diseases. J Perinat Med. 2018 Apr 25;46(3):293-8.

13. Silversides CK, Grewal J, Mason J, Sermer M, Kiess M, Rychel V, et al. Pregnancy Outcomes in Women With Heart Disease: The CARPREG II Study. J Am Coll Cardiol. 2018 May 29;71(21):241930.

14. Wald RM, Silversides CK, Kingdom J, Toi A, Lau CS, Mason J, et al. Maternal Cardiac Output and Fetal Doppler Predict Adverse Neonatal Outcomes in Pregnant Women With Heart Disease. J Am Heart Assoc Cardiovasc Cerebrovasc Dis. 2015 Nov 23;4(11):1-11.

15. Siu SC, Sermer M, Colman JM, Alvarez AN, Mercier LA, Morton BC, et al. Prospective multicenter study of pregnancy outcomes in women with heart disease. Circulation. 2001 Jul 31;104(5):515-21.

16. Silversides CK, Colman JM, Sermer M, Siu SC. Cardiac risk in pregnant women with rheumatic mitral stenosis. Am J Cardiol. 2003 Jun 1;91(11):1382-5.

17. Dolgun ZN, Inan C, Sayin NC. Maternal and fetal outcomes in pregnancies with pulmonary hypertension: Experience of a tertiary center. Taiwan J Obstet Gynecol. 2018 Feb;57(1):13-7.

18. Opotowsky AR, Siddiqi OK, D’Souza B, Webb GD, Fernandes SM, Landzberg MJ. Maternal cardiovascular events during childbirth among women with congenital heart disease. Heart $\mathrm{Br} \mathrm{Card}$ Soc. 2012 Jan;98(2):145-51.

19. Lima FV, Yang J, Xu J, Stergiopoulos K. National Trends and In-Hospital Outcomes in Pregnant Women With Heart Disease in the United States. Am J Cardiol. 2017 May 15;119(10):1694-700.

20. Briller J, Koch AR, Geller SE. Maternal Cardiovascular Mortality in Illinois, 2002-2011. Obstet Gynecol. 2017;129(5):819-26.

21. Hameed AB, Lawton ES, McCain CL, Morton CH, Mitchell C, Main EK, et al. Pregnancy-related cardiovascular deaths in California: beyond peripartum cardiomyopathy. Am J Obstet Gynecol. 2015 Sep;213(3):379.e1-10.

22. Martins LC, Freire CMV, Capuruçu CAB, Nunes M do CP, Rezende CA de L. Risk Prediction of Cardiovascular Complications in Pregnant Women With Heart Disease. Arq Bras Cardiol. 2016 Apr;106(4):289-96.

23. Samiei N, Amirsardari M, Rezaei Y, Parsaee M, Kashfi F, Hantoosh Zadeh S, et al. Echocardiographic Evaluation of Hemodynamic Changes in Left-Sided Heart Valves in Pregnant Women With Valvular Heart Disease. Am J Cardiol. 2016 01;118(7):1046-52. 
24. Anthony J, Osman, A, Sani MU. Valvular heart disease in pregnancy. Cardiovasc J Afr. 2016;27(2):111-8.

25. Garcia M, Mulvagh SL, Merz CNB, Buring JE, Manson JE. Cardiovascular Disease in Women: Clinical Perspectives. Circ Res. 2016 Apr 15;118(8):1273-93.

26. van Hagen IM, Thorne SA, Taha N, Youssef G, Elnagar A, Gabriel H, et al. Pregnancy Outcomes in Women With Rheumatic Mitral Valve Disease: Results From the Registry of Pregnancy and Cardiac Disease. Circulation. 2018 Feb 20;137(8):806-16.

27. Bhatla N, Lal S, Behera G, Kriplani A, Mittal S, Agarwal N, et al. Cardiac disease in pregnancy. Int J Gynaecol Obstet Off Organ Int Fed Gynaecol Obstet. 2003 Aug;82(2):153-9.

28. Roos-Hesselink JW, Budts W, Walker F, De Backer JFA, Swan L, Stones W, et al. Organisation of care for pregnancy in patients with congenital heart disease. Heart Br Card Soc. 2017;103(23):1854-9.

29. van Hagen IM, Roos-Hesselink JW, Donvito V, Liptai C, Morissens M, Murphy DJ, et al. Incidence and predictors of obstetric and fetal complications in women with structural heart disease. Heart $\mathrm{Br}$ Card Soc. 2017 Oct;103(20):1610-1618.

30. Adams Waldorf KM, Singh N, Mohan AR, Young RC, Ngo L, Das A, et al. Uterine overdistention induces preterm labor mediated by inflammation: observations in pregnant women and nonhuman primates. Am J Obstet Gynecol. 2015 Dec;213(6):830.e1-830.e19.

31. Pieper PG, Balci A, Aarnoudse JG, Kampman MAM, Sollie KM, Groen H, et al. Uteroplacental blood flow, cardiac function, and pregnancy outcome in women with congenital heart disease. Circulation. 2013 Dec 3;128(23):2478-87.

\section{Tables}

\section{Table 1: Baseline characteristics}




\begin{tabular}{|c|c|}
\hline Age (years) & $32.55 \pm 5.6$ ( range: $19-43$ ) \\
\hline $\begin{array}{l}\text { Rural origin } \\
\text { Educational level }\end{array}$ & $\begin{array}{l}29 \text { patients (48\%) } \\
\text { Analphabetic (3.3\%), primary (53.3\%), secondary (38.3\%), } \\
\text { university (5\%) }\end{array}$ \\
\hline Medical Antecedent & $\begin{array}{l}\text { Hypertension: } 5 \text { patients }(8.3 \%) \\
\text { Diabetes: } 2 \text { patients }(3.3 \%) \\
\text { Coronary disease: } 1 \text { patient }(1.6 \%) \\
\text { Idiopathic thrombocytopenia: } 1 \text { patient }(1.6 \%) \\
2.16 \pm 1.15 \text { (range de } 1 \text { à } 6) \\
2.8 \pm 1.6 \text { (range: } 1 \text { et } 5 \text { ) }\end{array}$ \\
\hline Obstetric Antecedent & $\begin{array}{l}\text { Previous Caesarean section : } \\
\text { No: } 43 \text { patients }(73 \%) \text {, one CS: } 12 \text { patients (20\%), Two } \\
\text { CS: } 4 \text { patients }(7 \%) \\
\text { Miscarriage: } 21.7 \% \\
\text { In Utero death: } 1.7 \% \\
\text { Neonatal death: } 5 \% \\
\text { Preeclampsia: } 6.7 \% \\
\text { Gestational diabetes: } 3.4 \%\end{array}$ \\
\hline $\begin{array}{l}\text { Dyspnea during the First } \\
\text { Trimester }\end{array}$ & NYHA I: 49\%, NYHA II: 43\%, NYHA III: $8 \%$ \\
\hline $\begin{array}{l}\text { Diagnosis of valvular heart } \\
\text { disease }\end{array}$ & $\begin{array}{l}\text { Before pregnancy: } 29 \text { patients }(48 \%) \\
\text { During pregnancy: } 28 \text { patients }(46 \%) \\
\text { During labour: } 2 \text { patients }(3.2 \%) \\
\text { During the first week: } 1 \text { patient }(1.6 \%)\end{array}$ \\
\hline $\begin{array}{l}\text { Anaemia } \\
\text { Severe valve disease }\end{array}$ & $\begin{array}{l}40 \text { patients }(60 \%) \\
\text { MS: } 43 \text { patients }(67 \%) \text {, AS: } 7 \text { patients }(13 \%), \text { MR: } 6 \\
\text { patients }(10 \%), \text { MS+MR: } 1 \text { patients }(1.6 \%), \text { MS+AR: } 1 \\
\text { patients }(1.6 \%) \text { PS: } 1 \text { patients }(1.6 \%)\end{array}$ \\
\hline Mean PASP $(\mathrm{mmHg})$ & $50.8 \pm 16.03$ (range: $20-95$ ) \\
\hline $\begin{array}{l}\text { Anticoagulants in } \\
\text { therapeutic dosage before } \\
\text { or during pregnancy (\%) }\end{array}$ & 19 patients $(31.7 \%)$ \\
\hline Delivery & $\begin{array}{l}\text { CS: } 68 \% \text {, normal vaginal delivery: } 27 \% \text {, induced vaginal } \\
\text { delivery: } 5 \%\end{array}$ \\
\hline $\begin{array}{l}\text { Gestational week at } \\
\text { delivery(median, min, max) }\end{array}$ & 38 weeks (range:30-42) \\
\hline $\begin{array}{l}\text { Maternal Cardiac } \\
\text { complications } \\
\text { Obstetrical complications }\end{array}$ & $\begin{array}{l}\text { Heart failure (82\%), Arrhythmia ( } 2 \%) \text {, Embolic events } \\
(2 \%) \text {, Anticoagulants overdose }(2 \%) \\
\text { Haemorrhage }(13 \%) \text {, Preeclampsia }(13 \%) \text {, gestational } \\
\text { diabetes ( } 8 \%) \text {, premature birth threats }(65 \%) \text {, premature } \\
\text { rupture of membranes }(4 \%)\end{array}$ \\
\hline Neonatal complications & $\begin{array}{l}\text { Small-for-gestational-age (52\%), premature birth (33\%), } \\
\text { hospitalisation (14\%) }\end{array}$ \\
\hline
\end{tabular}

MS: mitral stenosis, A S: Aortic stenosis, MR: mitral regurgitation, AR: aortic regurgitation, PS: pulmonary stenosis, CS: Caesarean Section, PASP: mean pulmonary arterial systolic pressure

Table 2: Comparison of groups according to maternal cardiac complications (MCC) 


\begin{tabular}{llll}
\hline & MCC+(n=37) & MCC-(n=23) & $\mathrm{p}$ \\
\hline Mean Age (SD) & $33.4 \pm 5.5$ & $31.17 \pm 5.4$ & 0.13 \\
Rural origin (\%) & $22(59.5)$ & $23(30.4)$ & 0.029 \\
Low educational level (\%) & $26(70.3)$ & $8(34.8)$ & 0.007 \\
Parity & $2.45 \pm 1.21$ & $2.21 \pm 1.16$ & 0.038 \\
Gravidity & $3.16 \pm 1.81$ & $2.21 \pm 1.16$ & 0.01 \\
Nulliparity (\%) & $11(29.7)$ & $10(43.5)$ & 0,27 \\
Unwanted pregnancy (\%) & $21(56.7)$ & $9(39.1)$ & 0.184 \\
Unfollowed pregnancy (\%) & $29(79.3)$ & $20(87)$ & 0.31 \\
Hypertension before pregnancy (\%) & $3(8.1)$ & $2(8.6)$ & 0.64 \\
Valve disease revealed by pregnancy (\%) & $23(62.2)$ & $8(34.8)$ & 0.039 \\
NYHA $\geq 2$ (\%) & $21(56.8)$ & $10(43.5)$ & 0.31 \\
Atrial fibrillation & $18(48.6)$ & $5(21.7)$ & 0.037 \\
Multiple valve disease (\%) & $19(51.4)$ & $9(39.1)$ & 0.35 \\
Severe MS (\%) & $32(86.5)$ & $11(47.8)$ & 0.001 \\
Severe AS (\%) & $5(13.5)$ & $5(21.7)$ & 0.31 \\
Severe MR (\%) & $4(10.8)$ & $6(26.1)$ & 0.12 \\
Severe AR (\%) & $1(2.7)$ & $1(4.3)$ & 0.62 \\
LVEF (\%) & $57.4 \pm 7.2$ & $61.13 \pm 2.2$ & 0.011 \\
PASP (mmHg) & $57.29 \pm 15.8$ & $40.39 \pm 9.7$ & $<0.001$ \\
LA diameter(mm) & $52.72 \pm 7.35$ & $47.39 \pm 6.04$ & 0.005 \\
Anaemia ((\%) & $24(64.9)$ & $12(52.2)$ & 0.32 \\
\hline
\end{tabular}

AS: Aortic stenosis, AR: Aortic regurgitation, LVEF: Left ventricle ejection fraction, LA: Left atrium, MS: Mitral stenosis, MR: Mitral regurgitation, NYHA: New York Heart Association, PASP: Mean pulmonary arterial systolic pressure

Table 3: Predictors of maternal cardiac complications

\begin{tabular}{|c|c|c|c|c|c|c|}
\hline & \multicolumn{3}{|c|}{ Univariate regression } & \multicolumn{3}{|c|}{ Multivariate regression } \\
\hline & $\mathrm{p}$ & OR & IC $95 \%$ & $\mathrm{p}$ & OR & CI 95\% \\
\hline Parity & 0.016 & 2.09 & $\begin{array}{l}(1.14- \\
3.82)\end{array}$ & 0.023 & 2.41 & $(1.12-5.16)$ \\
\hline $\begin{array}{l}\text { Valve disease revealed by } \\
\text { pregnancy }\end{array}$ & 0.042 & 3.08 & $\begin{array}{l}(1.04- \\
9.11)\end{array}$ & 0.025 & 6.34 & $\begin{array}{l}(1.26- \\
31.77)\end{array}$ \\
\hline Severe Mitral stenosis & 0.002 & 6.98 & $(2-24.32)$ & 0.035 & 6.84 & $\begin{array}{l}(1.14- \\
41.05)\end{array}$ \\
\hline PASP (mmHg) & $<0.001$ & 1.1 & $\begin{array}{l}(1.04- \\
1.16)\end{array}$ & 0.01 & 1.08 & $(1.01-1.14)$ \\
\hline
\end{tabular}


PASP: pulmonary arterial systolic pressure

Table 4: Comparison of groups according to obstetric complications $(\mathrm{CO})$

\begin{tabular}{llll}
\hline Mean Age (SD) & $34 \pm 4.61$ & $31 \pm 5.87$ & 0.15 \\
Age>35years (\%) & $9(47.4)$ & $14(34.1)$ & 0.32 \\
Rural Origin (\%) & $8(42.1)$ & $21(51.2)$ & 0.51 \\
Parity & $2.15 \pm 1.3$ & $2.17 \pm 1.09$ & 0.67 \\
Nulliparity & $9(47.4)$ & $12(29.3)$ & 0.17 \\
Gravidity & $2.84 \pm 1.67$ & $2.78 \pm 1.66$ & 0.88 \\
Unwanted pregnancy (\%) & $10(52.6)$ & $20(48.8)$ & 0.78 \\
None followed pregnancy (\%) & $4(21.1)$ & $7(17.1)$ & 0.48 \\
Hypertension (\%) & $2(10.5)$ & $3(7.3)$ & 0.51 \\
Diabetes (\%) & $1(5.3)$ & $1(2.4)$ & 0.53 \\
Pre-eclamptic toxaemia Antecedent (\%) & $2(10.5)$ & $2(4.9)$ & 0.37 \\
Caesarean antecedent (\%) & $8(42.1)$ & $8(19.5)$ & 0.06 \\
Abortion antecedent's (\%) & $5(26.3)$ & $8(19.5)$ & 0.39 \\
Valve disease revealed by pregnancy(\%) & $7(36.8)$ & $24(58.5)$ & 0.11 \\
NYHA 2 (\%) (\%) & $10(52.6)$ & $2(51.2)$ & 0.91 \\
Atrial fibrillation (\%) & $12(63.2)$ & $11(26.8)$ & 0.007 \\
Maternal cardiac complications (\%) & $14(73.7)$ & $23(56.1)$ & 0.19 \\
Multiple valve disease (\%) & $12(63.2)$ & $15(39)$ & 0.08 \\
Severe MS (\%) & $15(78.9)$ & $28(68.3)$ & 0.39 \\
Severe AS (\%) & $3(15.8)$ & $7(17.1)$ & 0.6 \\
Severe MR (\%) & $3(15.8)$ & $7(17.1)$ & 0.609 \\
Severe AR (\%) & $1(5.3)$ & $1(2.4)$ & 0.53 \\
LVEF (\%) & $60.26 \pm 3.1$ & $58.19 \pm 6.98$ & 0.42 \\
SAPS (mmHg) & $57.1 \pm 16.9$ & $47.9 \pm 14.9$ & 0.03 \\
LA diameter (mm) & $53.5 \pm 8.02$ & $49.4 \pm 6.7$ & 0.05 \\
Anaemia (\%) & $11(57.9)$ & $25(61)$ & 0.82 \\
Anticoagulant use (\%) & $11(57.9)$ & $8(19.5)$ & 0.003 \\
Diuretic use (\%) & $12(53.6)$ & $15(80)$ & 0.08 \\
Beta-blockers use (\%) & $6(40)$ & $4(14.3)$ & 0.057 \\
Cardiac events (\%) & $14(73.7)$ & $23(56.1)$ & 0.19 \\
\hline & & & \\
\hline
\end{tabular}

AS: Aortic stenosis, AR: Aortic regurgitation, LVEF: Left ventricle ejection fraction, LA: Left atrium, MS: Mitral stenosis, MR: Mitral regurgitation, NYHA: New York Heart Association, PASP: Mean pulmonary arterial systolic pressure

PASP: Mean pulmonary arterial systolic pressure 
Table 5: Predictors of obstetric complications

\begin{tabular}{lllllll}
\hline & \multicolumn{2}{l}{ Univariate regression } & \multicolumn{3}{l}{ Multivariate regression } \\
\hline & $\mathrm{p}$ & $\mathrm{OR}$ & $95 \% \mathrm{CI}$ & $\mathrm{p}$ & $\mathrm{OR}$ & $95 \% \mathrm{CI}$ \\
Nulliparity & 0.17 & 2.17 & {$[0.7-6.69]$} & 0.032 & 5.22 & {$[1.15-23.6]$} \\
Multiple valve disease & 0.081 & 2.67 & {$[0.87-8.24]$} & 0.028 & 5.26 & {$[1.19-23.2]$} \\
SASP (mmHg) & 0.04 & 1.03 & {$[1.001-1.076]$} & 0.041 & 1.04 & {$[1.002-1.09]$} \\
Anticoagulant use & 0.003 & 5.67 & {$[1.71-18.7]$} & 0.004 & 8.71 & {$[1.98-38.2]$} \\
\hline
\end{tabular}

Table 6: Comparison of groups according to neonatal complications (NC)

\begin{tabular}{llll}
\hline & $\mathrm{NC}(\mathrm{n}=23)$ & $\mathrm{NC}-(\mathrm{n}=37)$ & P value \\
\hline Age (years) & $32.56 \pm 4.69$ & $32.54 \pm 6.09$ & 0.98 \\
Rural origin (\%) & $12(52.2)$ & $17(45.9)$ & 0.63 \\
Low educational level (\%) & $12(52.2)$ & $22(59.5)$ & 0.58 \\
Parity & $2.3 \pm 1.06$ & $2.08 \pm 1.21$ & 0.67 \\
Gravidity & $3.13 \pm 1.63$ & $2.59 \pm 1.65$ & 0.88 \\
Unwanted pregnancy (\%) & $13(56.5)$ & $17(45.9)$ & 0.42 \\
unfollowed pregnancy (\%) & $19(82.6)$ & $30(91.1)$ & 0.58 \\
Hypertension before pregnancy (\%) & $3(13)$ & $2(5.4)$ & 0.28 \\
Valve disease revealed by pregnancy (\%) & $15(65.2)$ & $16(43.2)$ & 0.09 \\
NYHA 2 (\%) & $14(60.9)$ & $17(45.9)$ & 0.26 \\
Atrial fibrillation (\%) & $12(52.2)$ & $11(29.7)$ & $\mathrm{P}<0.001$ \\
Maternal cardiac events (\%) & $19(82.6)$ & $18(48.61)$ & 0.005 \\
Multiple valve disease (\%) & $11(47.8)$ & $17(45.9)$ & 0.88 \\
Severe MS (\%) & $18(78.3)$ & $25(67.6)$ & 0.37 \\
Severe AS (\%) & $3(13)$ & $7(18.9)$ & 0.41 \\
Severe MR (\%) & $4(17.4)$ & $6(16.2)$ & 0.9 \\
Severe AR (\%) & $1(4.3)$ & $1(2.7)$ & 0.95 \\
LVEF (\%) & $53.95 \pm 8.55$ & $59.5 \pm 3.79$ & 0.42 \\
PASP (mmHg) & $58 \pm 16.5$ & $45 \pm 13.8$ & 0.002 \\
LA diameter(mm) & $52.9 \pm 8.4$ & $49.29 \pm 6.2$ & 0.06 \\
Anaemia (\%) & $15(65.2)$ & $21(56.8)$ & 0.51 \\
Hemoglobin (g/dl) & $10.17 \pm 1.24$ & $10.36 \pm 1.22$ & 0.98 \\
Anticoagulant use (\%) & $14(60.9)$ & 27.73 & 0.32 \\
Cardiac events (\%) & $19(82.6)$ & $18(48.6)$ & 0.009 \\
Obstetric events (\%) & $13(56.5)$ & $6(16.2)$ & 0.001 \\
\hline
\end{tabular}

AS: Aortic stenosis, AR: Aortic regurgitation, LVEF: Left ventricle ejection fraction, LA: Left atrium, MS: Mitral stenosis, MR: Mitral regurgitation, NYHA: New York Heart Association, PASP: Mean pulmonary arterial systolic pressure

Table 7: Predictors of neonatal complications

\begin{tabular}{|c|c|c|c|c|c|c|}
\hline & \multicolumn{3}{|c|}{ Univariate regression } & \multicolumn{3}{|c|}{ Multivariate regression } \\
\hline Obstetric events & $\begin{array}{l}\mathrm{p} \\
0.002\end{array}$ & $\begin{array}{l}\text { OR } \\
6.71\end{array}$ & $\begin{array}{l}\text { IC 95\% } \\
{[2.02--}\end{array}$ & $\begin{array}{l}\mathrm{p} \\
0.001\end{array}$ & $\begin{array}{l}\mathrm{OR} \\
15.48\end{array}$ & $\begin{array}{l}\text { CI 95\% } \\
{[2.99-} \\
8012]\end{array}$ \\
\hline $\begin{array}{l}\text { Valve disease revealed by } \\
\text { pregnancy }\end{array}$ & 0.1 & 2.46 & [0.83-7.22] & 0.017 & 6.95 & [1.4-34.3] \\
\hline
\end{tabular}


Table 8: Predictors of cardiac, obstetric and foetal events in literature

\begin{tabular}{|c|c|c|c|c|}
\hline & $\begin{array}{l}\text { CAPREG I } \\
(8)\end{array}$ & ROPAC REGISTRY [3] & CAPREG II [13] & Our Study \\
\hline Study Period & $1994-1999$ & $2008-2014$ & $2001-2014$ & $2010-2017$ \\
\hline $\begin{array}{l}\text { Publication } \\
\text { year }\end{array}$ & 2001 & 2016 & 2018 & - \\
\hline Methodology & $\begin{array}{l}\text { Prospective } \\
\text { (Canadian } \\
\text { registry) }\end{array}$ & $\begin{array}{l}\text { Prospective (multicenter } \\
\text { European Registry) }\end{array}$ & $\begin{array}{l}\text { Prospective cohort } \\
\text { (Canadian registry) }\end{array}$ & $\begin{array}{l}\text { Retrospective } \\
\text { cohort }\end{array}$ \\
\hline Population & $\begin{array}{l}\mathrm{N}=599 \\
\text { (congenital } \\
\text { and acquired } \\
\text { disease) }\end{array}$ & $\mathrm{N}=2742, \mathrm{VHD}=865$ & $N=1938$ & $\begin{array}{l}\mathrm{N}=60 \text { severe } \\
\text { valve disease }\end{array}$ \\
\hline Age (years) & $28 \pm 6$ & $29.2 \pm 5.5$ & $30.6 \pm 5.6$ & $32.5 \pm 5.6$ \\
\hline $\begin{array}{l}\text { MCC } \\
\text { incidence }\end{array}$ & $13 \%$ & $20.6 \%$ & $16 \%$ & $61 \%$ \\
\hline $\begin{array}{l}\text { Independent } \\
\text { Predictors of } \\
\text { MCC }\end{array}$ & $\begin{array}{l}\text { *Cardiac } \\
\text { disease } \\
\text { antecedent } \\
\text { *NYHA } \geq 2 \\
\text { /cyanosis } \\
\text { *Left heart } \\
\text { obstruction } \\
\text { *LVEF } \leq 40 \%\end{array}$ & $\begin{array}{l}* \text { Pre-pregnancy signs of heart } \\
\text { failure } \\
\text { *in advanced countries. atrial } \\
\text { fibrillation and no previous } \\
\text { cardiac intervention }\end{array}$ & $\begin{array}{l}\text { *Prior cardiac events or } \\
\text { arrhythmias. } \\
\text { *poor functional class or } \\
\text { cyanosis. } \\
\text { *high-risk valve } \\
\text { disease/left ventricular } \\
\text { outflow tract } \\
\text { obstruction. } \\
\text { *systemic ventricular } \\
\text { dysfunction. } \\
\text { *no prior cardiac } \\
\text { interventions. } \\
\text { *Mechanical valves. } \\
\text { *high-risk aortopathies. } \\
\text { *pulmonary } \\
\text { hypertension. } \\
\text { *late pregnancy } \\
\text { assessement }\end{array}$ & $\begin{array}{l}\text { *Parity } \\
\text { *Revelation of } \\
\text { the valve disease } \\
\text { by pregnancy } \\
\text { *Mitral stenosis } \\
\text { *Systolic } \\
\text { pulmonary } \\
\text { hypertension }\end{array}$ \\
\hline $\begin{array}{l}\text { OC } \\
\text { incidence }\end{array}$ & $7 \%$ & $8.4 \%$ & - & $31 \%$ \\
\hline Independent & *Primiparity & *Primiparity. & - & *Nulliparity \\
\hline $\begin{array}{l}\text { Predictors of } \\
\text { OC }\end{array}$ & $\begin{array}{l}\text { *Aortic } \\
\text { coarctation. } \\
\text { *lupus } \\
\text { *Anticoagulant } \\
\text { use. } \\
\text { *cyanosis }\end{array}$ & $\begin{array}{l}\text { *hypertension before } \\
\text { pregnancy }\end{array}$ & & $\begin{array}{l}\text { *PASP } \\
* \text { Anticoagulant } \\
\text { use } \\
\text { *Multiple valve } \\
\text { disease }\end{array}$ \\
\hline $\begin{array}{l}\mathrm{NC} \\
\text { incidence }\end{array}$ & $20 \%$ & $23.7 \%$ & - & $40 \%$ \\
\hline $\begin{array}{l}\text { Independent } \\
\text { predictors of } \\
\text { NC }\end{array}$ & $\begin{array}{l}\text { Multigestity } \\
\text { NYHA II or } \\
\text { cyanosis } \\
\text { Anticoagulant } \\
\text { use } \\
\text { Tabagism } \\
\text { Left heart } \\
\text { obstruction }\end{array}$ & $\begin{array}{l}\text { Multigestity } \\
\text { Anticoagulant use } \\
\text { Pregnancy in underdeveloped } \\
\text { countries }\end{array}$ & - & $\begin{array}{l}\text { Maternal cardiac } \\
\text { complications } \\
\text { Valve disease } \\
\text { revealed by } \\
\text { pregnancy }\end{array}$ \\
\hline
\end{tabular}

LVEF: Left Ventricle ejection Fraction, MCC maternal cardiac complications, NC: Neonatal complications, NYHA: New York Heart Association, OC obstetrical Complications, VHD: valve 
heart disease,

\section{Supplementary Files}

This is a list of supplementary files associated with this preprint. Click to download.

- fichespss.sav 